\title{
A Typology of Digital Sharing Business Models: A Design Science Research Approach
}

Pouri, Maria ; Hilty, Lorenz

\begin{abstract}
The digitally enabled sharing economy, also called the "digital sharing economy" (DSE), has changed patterns of consumption by introducing new choices and channels for provision and receipt of services. The DSE encompasses sharing systems whose business models may vary distinctly from platform to platform. Although business models in the context of the sharing economy have been studied so far, we have observed that the current literature does not provide an approach that covers all the possible business models (in the broadest sense of the term) that (potentially) exist within the scope of the DSE. The present paper, therefore, aims to propose a typology of business models in the DSE that covers a wide space of models - even those which may not involve "business" in the commercial sense. This is achieved through an iterative inductive process based on a design science research approach. The typology can assist in positioning the current and future sharing systems in the DSE by systematically classifying their business models. It is intended to serve as a guiding tool for the sustainability assessment of platforms from both resource and socio-economic perspectives. The present study can also enable researchers and practitioners to capture and systematically analyse digital sharing business models based on a structured, actionable approach.
\end{abstract}

Posted at the Zurich Open Repository and Archive, University of Zurich

ZORA URL: https://doi.org/10.5167/uzh-189818

Conference or Workshop Item

Accepted Version

Originally published at:

Pouri, Maria; Hilty, Lorenz (2020). A Typology of Digital Sharing Business Models: A Design Science Research Approach. In: 15th International Conference on Design Science Research in Information Systems and Technology (DESRIST) 2020, Kristiansand, Norway, 2 December 2020 - 4 December 2020, Springer. 


\title{
A Typology of Digital Sharing Business Models: A Design Science Research Approach
}

\author{
Maria J. Pouri ${ }^{1}$ and Lorenz M. Hilty ${ }^{1,2}$ \\ ${ }^{1}$ Department of Informatics, University of Zurich, 8050 Zurich, Switzerland \\ 2 Technology and Society Lab, Empa Materials Science and Technology, 8600 Dübendorf, \\ Switzerland \\ pouri@ifi.uzh.ch
}

\begin{abstract}
The digitally enabled sharing economy, also called the 'digital sharing economy' (DSE), has changed patterns of consumption by introducing new choices and channels for provision and receipt of services. The DSE encompasses sharing systems whose business models may vary distinctly from platform to platform. Although business models in the context of the sharing economy have been studied so far, we have observed that the current literature does not provide an approach that covers all the possible business models (in the broadest sense of the term) that (potentially) exist within the scope of the DSE. The present paper, therefore, aims to propose a typology of business models in the DSE that covers a wide space of models - even those which may not involve business in the commercial sense. This is achieved through an iterative inductive process based on a design science research approach. The typology can assist in positioning the current and future sharing systems in the DSE by systematically classifying their business models. It is intended to serve as a guiding tool for the sustainability assessment of platforms from both resource and socio-economic perspectives. The present study can also enable researchers and practitioners to capture and systematically analyse digital sharing business models based on a structured, actionable approach.
\end{abstract}

Keywords: Digital Sharing Economy, Business Models, Typology, Sharing Platforms, Sharing Systems, Design Science Research, Sustainability.

\section{Introduction}

Since Lessig [1] has mentioned the term 'sharing economy' in his work, there has been a proliferation of studies proposing definitions for it (e.g. [2-5]). Several studies have reviewed these definitions (e.g. [6-8]). The present work is based on the approach taken by the authors in [9] in which the digitally enabled sharing economy, or the digital sharing economy (DSE), is conceptualized as a manifestation of the digital transition of society and defined as: "A class of resource allocation systems based on sharing practices which are coordinated by digital online platforms and performed by individuals and possibly (non-) commercial organizations with the aim to provide

This Accepted Author Manuscript is copyrighted by Springer.

Citation: Pouri, M.J., Hilty, L.M. (Forthcoming). A Typology of Digital Sharing Business Models: A Design Science Research Approach. Proceedings of 15th International Conference on Design Science Research in Information Systems and Technology (DESRIST) 2020. 
access to material and immaterial resources. Digital sharing systems operate in the space between traditional sharing and the formal economy" [9].

The DSE has created a "new culture of sharing" $[10,11]$ whereby individuals collaborate in resource distribution in their peer networks rather than being purely dependent on services from the formal market [12]. Moreover, even in business-toconsumer sharing models, it appears that sharing is becoming increasingly popular and even preferred to their conventional (non-sharing) counterparts.

Typically, sharing platforms offer a wide variety of services which are often more affordable, efficient, convenient, and accessible than their counterparts in the conventional market; hence more attractive in the eyes of consumers. The move towards sharing modes of consumption can be viewed as expressing a shift of consumers' mindsets [13], expectations and values [14] on which sharing business models are based [15]. Business models support the provision of value to customers $[16,17]$. From a business model perspective, it is therefore important to see how sharing platforms create value, and how this value is perceived and distributed across the sharing system [15].

Given that the DSE is an umbrella term for different sharing systems [18], its business models (BMs) can vary from platform to platform, targeting different mechanisms for value (co-)creation. Therefore, BMs in the DSE can substantially differ from one another.

We aim to design a typology for digital sharing BMs that can encompass the broad spectrum of sharing systems. In other words, our objective is to design a typology that looks at the BMs of sharing systems from a perspective that is open for various ways of practicing sharing and creating value. We think that such a typology can be useful to conceptualize and visualize the fundamental, common attributes of sharing systems and to systematically classify them by showing how they differ in the attribute values of their BM components. The result can particularly help platform providers to position themselves in the spectrum of market and non-market based sharing models, and to tap into (new) practicable BM opportunities [19] in the area of the DSE. Another use case of our typology can be to apply it as a first step in systematic sustainability assessments of sharing platforms.

This paper proceeds as follows: Section 2 provides an overview of related work on the concept of BM in general, and on the study of sharing business models in particular. Subsequent to Section 3, where we explain our research methodology, we describe the development of our proposed typology of sharing business models in Section 4. In Section 5, we discuss how the typology could be used to describe value in sharing and to direct the assessment of sustainability impacts of sharing from a structured BM approach. The paper closes with concluding remarks and an outlook for future work.

\section{Related Work}

Although mentions of the term 'business model' in scientific work dates back to late 50s (e.g. in [20] cited in [21]), it was during the mid-90s when the term turned into a buzzword in the business area, and in the late 90s when it particularly came to attention with the commercialization of the Internet [21]. As the literature on BMs is 
heterogeneous, there is no generally accepted definition of the BM concept yet [22-24]. Nevertheless, BM is a concept often used to describe how a firm works [25].

The BM concept is of practical and economic importance [21] and is considered an integral part of economic behaviors [26]. Although BMs have been usually studied in the context of commercial enterprises and conceived as a commercial logic of value capture and proposition [27], their concept can be applied also to non-commercial enterprises, governance models, and initiatives such as social innovation $[15,28]-$ wherein the DSE is known to have roots [29] - or in the context of actions for sustainability [30].

BMs have been discussed also in the context of the DSE (e.g. [31-34]). Some studies have researched the BM of one particular sharing platform (e.g. [35] for Airbnb and [36] for Uber), of a set of various platforms (e.g. [37]), or the BMs within a particular domain such as mobility (e.g. [31]). Others have come up with classifications for platforms in the DSE. For example, Barbu et al. [38] classify sharing business models into three main types: access-based, marketplace/platform economy, and on-demand service provider. Building on different configurations of initiatives (or platforms), contributors, peers, and users, Acquier at al. [15] propose a typology of four different BM configurations of sharing platforms. Their typology classifies platforms as commoners, mission-driven, shared infrastructure, and matchmakers. In the present paper, by including other BM components (such as basic types of sharable resources and sharing practices) and by differentiating between categories of participants, we intend to extend the typologies that already exist in the literature. For each component, we will identify its possible attribute values. The result is a typology of digital sharing BMs.

\section{Method}

\subsection{Exploratory Study}

For the present study, we used a list of platforms that are currently operating under the 'sharing economy' label. Due to space constraints, we cannot provide this full list which we have been using for other research purposes as well. Nevertheless, in Appendix 1, we show a sample of platforms in the DSE taken from this list to illustrate the spectrum of encountered business models.

For the sake of completeness and transparency, we briefly explain the exploratory part of our research methodology. To prepare the initial comprehensive list of platforms, we followed a systematic search and collected any platform brand that is known as part of - or claimed to belong to - the sharing economy by searching for the term 'sharing economy' and related terms (e.g., 'collaborative consumption' [39], 'peer economy' [40], 'platform economy' [41], 'access-based consumption' [42], 'crowdbased capitalism' [43], 'gig economy' [44]). At this stage, our aim was to include as many platforms as possible in order to reach the most inclusive sample of platforms that are known to represent the phenomenon from literature or practice. This process of aggregating platforms was stopped when no further new types of sharing systems or patterns were found. At a second stage, we modified the list by eliminating the platforms that did not follow the principles of the DSE as conceptualized by the authors 
in [9]. For example, platforms whose services involve change of ownership, redistribution, or gifting/donating were removed. Appendix 1 shows an excerpt from this reduced list.

\subsection{Design Science Research Approach}

After the exploratory step described above, we followed a design science research (DSR) method to develop the artifact, i.e. the typology for sharing business models. DSR aims to add to knowledge of how things can be designed [45]. It is particularly useful and applicable for designing artifacts relevant to digital innovation [45, 46]. In addition, considering that the DSE could be primarily viewed as an innovation that leverages digitally enabled solutions [47] to develop innovative businesses [37], we found the DSR method most compatible and applicable to the focus of our study. Previous work has also adopted this approach for developing business models as the targeted artifact in the context of digital innovation, e.g. for designing Internet of things (IoT) business models [19].

Throughout the design stage, we adhered to the DSR approach and guidelines as defined by Hevner [48] and followed his three-cycle view: the relevance cycle, the rigor cycle, and the design cycle. The relevance cycle of DSR initiates the research in a relevant application context in which the research problem takes place. The rigor cycle ensures a meaningful connection between the new research and past knowledge (i.e. the existing experiences, expertise, artifacts, processes, theories, etc.) and justifies the innovation and contribution of the research. The design cycle iterates between building the artifact and its evaluation - together with the subsequent feedbacks to refine the design - and keeps dependencies on the relevance and rigor cycles. In the following section, we will elaborate on how we implemented these cycles.

\section{Artifact Development}

\subsection{Business Model Elements of the DSE}

Here, we explain the results of the exploratory study of sharing platforms (as described in 3.1) by presenting a conceptualization of the DSE based on the classification of the following properties in the platforms under study:

- resource providers (who shares);

- resource receivers (with whom to share);

- sharable resources (what is shared);

- the socio-economic mechanism that allows the act of sharing to happen (how to share).

Resource providers can be: individuals, businesses (i.e. commercial enterprises), nonprofit enterprises, and the public sector; the same applies for resource receivers. 
We classify sharable resources in four broad categories: durable material goods (e.g., car, a tool), consumable material goods (e.g., food, fuel), durable immaterial goods (competence and durable information goods), and consumable immaterial goods (time and consumable information goods). Important sub-categories are durable information goods such as software [49] or timeless content that we distinguish (albeit not sharply) from consumable immaterial goods, which lose their value over time. The latter is true for news or the information shared in community-based participatory sensing systems [50].

To differentiate between sharing practices, we use the concepts of reciprocity and compensation as the practical mechanisms for sharing [9]. All possible sharing practices in the DSE seem to belong to one of the following four classes:

1. Practices without reciprocity or compensation.

2. Practices with informal reciprocity or compensation: The receiver of a service is recommended (not enforced) to offer an equivalent service or a compensation to the provider or to the community at some point.

3. Practices with formal reciprocity or compensation: The receiver of a service is enforced to offer an equivalent service or a compensation to the provider or to the community at some point.

4. Practices with formal monetary compensation to the provider per service received.

This conceptualization addresses the basic elements required for designing a BM; the what, who, with whom, and how of sharing. These elements of sharing platforms could be mapped to the general archetypal business model approach by Gassmann et al. [51], in which the following elements are taken into consideration: targeted consumers (resource providers and receivers in the case of sharing platforms), what is offered to them (sharable resources), and practices that distribute the value (sharing practices).

\subsection{Building the typology}

The rationale for pursuing the present research lies in the importance of the DSE from a sustainability perspective. Although it is often viewed or expected to be an enabler of positive changes towards mitigating the currently unsustainable consumption patterns, the DSE keeps raising concerns about the sustainability of the consumption modes and the socio-economic activities it promotes [3, 52-54 $]^{1}$. Therefore, we seek to address the problem of assessing sustainability impacts of the DSE. This indicates that the intended application context of our artifact is the sustainability assessment of digital sharing systems (initiating relevance) [12].

Solutions produced by DSR should be generalizable, i.e. to be applicable to a same class of problems [60]. It is possible that both the problem (which here is assessing the sustainability impacts of the DSE) and the solution (here to model the DSE in a way

${ }^{1}$ For more studies on the relevance of the DSE for sustainability, see [12, 55-59]. 
that is helpful for the assessment of the sustainability impacts of its multifaceted manifestations) are general [61]. This is compatible with our partially inductive process of defining sharing types. The result, which is a general typology, would be then applicable to all manifestations of the DSE because it allows to classify its platforms by means of the typology.

To keep rigor, we have mainly depended on literature. An ample number of studies on the sharing economy were reviewed by the authors (to name a few [2-8, 55, 62-66]). Additionally, we are aware of the conceptual dissent and the theoretical disputes about the sharing economy (e.g. [67, 68]). The authors developed a conceptual framework for the DSE in [9], which was chosen here as a theoretical reference due to its inclusive DSE concept which integrates many of the existing categorizations of digital sharing systems.

Regarding the evaluation cycle, we examined each iteration of the design based on the criteria for the purpose of BMs ([69] cited in [21]) by checking if the types of platforms were still understandable as meaningful BMs. As a classification scheme, the primary function of a typology is to construct classes about which we make inductive generalizations [70]. We evaluated our proposed typology with Lambert's criteria for useful classification schemes [70, 71]: The typology reduced the complexity of the heterogeneity of digital sharing BMs by identifying the similarities and differences among them. It also created the possibility to compare different BMs through the presentation of the dimensions (or BM components) and their range of attribute values. Since it makes explicit various aspects of the DSE in a BM context, the typology demonstrates multi-functionality to suit multiple needs, in particular to help structuring the sustainability assessment of digital sharing BMs.

Each cycle of the artifact design iterated "between the core activities of building and evaluating the design artifacts and processes of the research." [48, p. 2], as foreseen in the DSR paradigm. Our design cycle was an iterative inductive and deductive process: inductive because we started from studying individual sharing systems, and deductive because we conceptualized sharing platforms based on a theoretical approach that we present in [9].

The results of the conceptualization of platforms in the DSE (as described in part 4.1) were arranged, i.e. designed [45], through the DSR method in a 4-dimensional visual representation of the resource provider (from), resource receiver (to), shared resource (what) and sharing practice (how) aspects of sharing BMs in the DSE, as shown in Figure 1. 


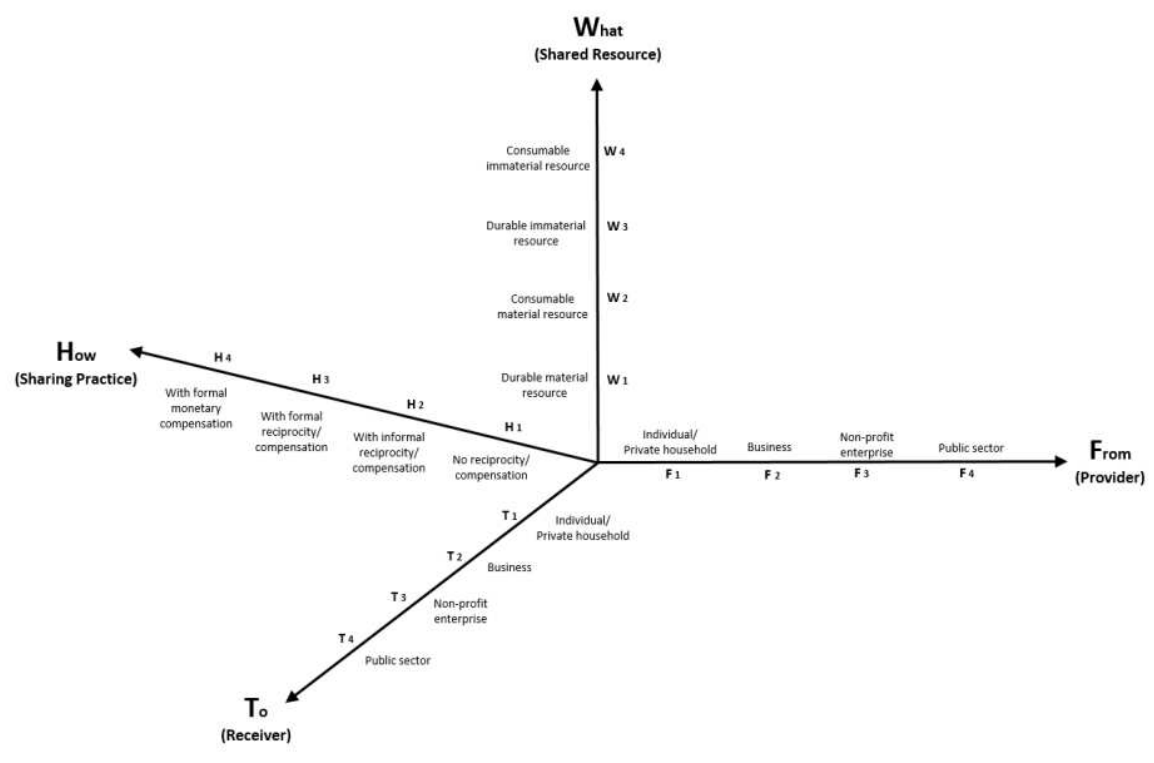

Fig. 1. A proposed typology for digital sharing business models.

We expect that any instance of the DSE can be represented in this 4D space and thus denoted by its "BM code", which is a vector in the "FTWH space". For example, the typical Uber riding service can be represented as follows:

BM Code of Uber: (F1, T1, W1, H4)

Appendix 1 includes the BM codes of additional examples of sharing platforms.

\section{Discussion}

The typology introduced above was built based on the required BM elements of sharing platforms from a holistic DSE perspective. The four dimensions do not include a why dimension because the reasons why participation in sharing takes place can be inferred from the other dimensions plus some assumptions about the value perceived by the participants that motivates them to use services [72, 73] offered by a sharing platform. Thus, the why question is located at a higher level of description. Recalling that BMs support the provision of value to customers $[16,17]$, we can describe with our typology what resource and what sharing practice combine to create a perceived value in the interaction between providers and receivers. What the perceived value actually is will then be inferred. To illustrate this, we resume the Uber example. In the case of Uber's typical riding service, a durable material resource (a car) is shared between an individual resource owner (the driver) and an individual resource receiver (the rider) for a certain fare for the riding service received (a formal monetary compensation). This 
can tell us about the motivation for users' participation, or the main value offered by the platform, which is normally to receive a cheaper riding service (compared to conventional taxi services) for the rider $^{2}$ and to earn an extra income for the driver. Therefore, the prime value for using this platform, and the similar ones, could be to benefit from the economic value of sharing [75]. It is notable that platforms do not necessarily create only one type of value for their consumers. Sharing via digital platforms may hold a combination of various value propositions, such as efficiency, convenience, enjoyment, reputation, a sense of community $[76,77]$ and others as well.

From a sustainability perspective, it is important to bear two aspects in mind [78]: 1) The implications of shared consumption of resources: For example, if the economic value of sharing decreases the unit price of the service for the user, this can trigger additional demand for the same service (direct rebound effect) or for other services (indirect rebound effect). Thus, the rebound effect may partially or completely balance out the favorable effects of shared consumption, which are usually referred to as optimization effects of sharing [79]. Such effects of digitalization can better be captured with dynamic modelling - as done in [80], an early study which however did not consider the DSE yet. 2) The implications of the specific sharing practices for the participants: For example, whether resource providers and receivers in the DSE are in a social position that is better or worse than before (e.g., regarding fair access to resources and markets, participation in cultural life, labor conditions) [12]. Sharing BMs can create issues related to consumer and labor protection $[44,52]$ and the promotion of tax avoidance [52]. With regard to underpayment and low wages, the DSE has been labeled as the "share-the-scraps economy" where most of the profits goes to the platform owners and the scraps go to the workers [81]. Apparently, the depth of the assessment in this aspect should go further in detail based on a particular sharing platform and the social and economic practices it promotes.

This way, our typology of digital sharing BMs can work as an interface to tap into the possible opportunities for value creation in sharing systems and to direct the assessment of sustainability impacts of them.

\section{Conclusion and Outlook}

In the present work, we proposed a typology for classifying digital sharing platforms from a business model perspective. To develop this typology, we adopted a design science research approach. The artifact we designed - i.e. the typology for digital sharing business models - demonstrates descriptive power by creating a simple yet expressive language for differentiating $4^{4}=256$ theoretical types of digital sharing systems.

The relevance of this artifact comes from the insight that digital sharing systems operate in the space between traditional sharing and the formal economy and can generate non-monetary or monetary value for their participants. This not only opens a

\footnotetext{
${ }^{2}$ Exceptions may be observed when dynamic pricing models become effective especially in peerto-peer services. Dynamic pricing is already practiced in Uber's "Surge pricing" or in Lyft's "Prime Time", where a consumer faces prices ranging from a base price to multiples of that price [74], which in principle can exceed a conventional taxi fare.
} 
wide space for potential business models in the DSE, but also creates opportunities as well as risks when viewed from a sustainability perspective.

Our typology can provide guidance for entrepreneurs and also for established businesses that aim to implement potential business models in the DSE realm. It can also assist policymakers and public actors in regulating and supporting the implementation of digital sharing schemes that can envision sustainability scenarios in which organizations are able to operate in an environmentally compatible way that promotes life-enhancing social and economic activities. Future work may refine the proposed typology to make even finer-grained differentiations. We hope that this research will inspire the design of innovative business models that promote responsible, sustainable activities in the digital sharing economy.

\section{References}

1. Lessig L (2008) Remix: making art and commerce thrive in the hybrid economy. Penguin, New York.

2. Koopman, C., Mitchell, M. and Thierer, A., 2015. The sharing economy and consumer protection regulation: The case for policy change. J. Bus. Entrepreneurship \& L., 8, p.529Koopman, C., Mitchell, M. and Thierer, A., 2015. The sharing economy and consumer protection regulation: The case for policy change. J. Bus. Entrepreneurship \& L., 8, p.529.

3. Frenken, K. and Schor, J., 2017. Putting the sharing economy into perspective. Environmental Innovation and Societal Transitions, 23, pp.3-10.

4. Ranjbari, M., Morales-Alonso, G. and Carrasco-Gallego, R., 2018. Conceptualizing the sharing economy through presenting a comprehensive framework. Sustainability, 10(7), p.2336.

5. Rachel Botsman. 2013. The sharing economy lacks a shared definition. (2013). https://www.fastcompany.com/3022028/the-sharing-economy-lacks-a-shared-definition, last accessed 2020/04/25.

6. Dillahunt, T.R., Wang, X., Wheeler, E., Cheng, H.F., Hecht, B. and Zhu, H., 2017. The sharing economy in computing: A systematic literature review. Proceedings of the ACM on HumanComputer Interaction, 1(CSCW), pp.1-26.

7. Oh, S. and Moon, J.Y., 2016, August. Calling for a shared understanding of the" sharing economy". In Proceedings of the 18th Annual International Conference on Electronic Commerce: e-Commerce in Smart connected World (pp. 1-5).

8. Görög, G., 2018. The Definitions of Sharing Economy: A Systematic Literature Review. Management (18544223), 13(2).

9. Pouri, M.J., Hilty, L.M.: The Digital Sharing Economy: A Confluence of Technical and Social Sharing. Submitted for publication.

10. Bucher, E., Fieseler, C., \& Lutz, C. (2016). What's mine is yours (for a nominal fee) Exploring the spectrum of utilitarian to altruistic motives for internet-mediated sharing. Computers in Human Behavior, 62, 316-326.

11. Nadeem, W., Juntunen, M., Hajli, N. and Tajvidi, M., 2019. The Role of Ethical Perceptions in Consumers' Participation and Value Co-creation on Sharing Economy Platforms. Journal of Business Ethics, pp.1-21.

12. Pouri, M.J. and Hilty, L.M., 2018. Conceptualizing the digital sharing economy in the context of sustainability. Sustainability, 10(12), p.4453. 
13. Barbu, C.M., Florea, D.L., Ogarcă, R.F. and Barbu, M.C., 2018. From Ownership to access: How the sharing economy is changing the consumer behavior. Amfiteatru Economic, 20(48), pp.373-387.

14. WEF, World Economic Forum. (2018) https://www.weforum.org/agenda/2018/01/howconsumption-will-change-over-next-decade/, last accessed 2020/04/25.

15. Acquier, A., Carbone, V. and Massé, D., 2019. How to create value (s) in the sharing economy: Business models, scalability, and sustainability. Technology Innovation Management Review, 9(2).

16. Teece, D.J., 2010. Business models, business strategy and innovation. Long range planning, 43(2-3), pp.172-194.

17. Teece, D.J. and Linden, G., 2017. Business models, value capture, and the digital enterprise. Journal of Organization Design, 6(1), pp.1-14.

18. Codagnone, C. and Martens, B., 2016. Scoping the sharing economy: Origins, definitions, impact and regulatory issues. Cristiano Codagnone and Bertin Martens (2016). Scoping the Sharing Economy: Origins, Definitions, Impact and Regulatory Issues. Institute for Prospective Technological Studies Digital Economy Working Paper, 1.

19. Turber, S. and Smiela, C., 2014. A business model type for the internet of things.

20. Bellman, R., Clark, C., Craft, C., Malcolm, DG., and Ricciardi, F. 1957. "On the construction of a multistage, multi-person business game," Operations Research (5:4), pp. 469-503.

21. Burkhart, T., Krumeich, J., Werth, D. and Loos, P., 2011. Analyzing the business model concept - a comprehensive classification of literature.

22. Peric, M., Durkin, J. and Vitezic, V., 2017. The constructs of a business model redefined: A half-century journey. Sage Open, 7(3), p.2158244017733516.

23. Novak, A., 2014. Business model literature overview. Financial Reporting.

24. Xu, L. and Chen, J., 2011. Technological rules based business models analysis: a design science approach. International Journal of Business and Management, 6(9), p.113.

25. Haggege, M. and Collet, L., 2011, June. Exploring new business models with a narrative perspective. In 18th International Product Development Management Conference. Delft, Netherlands Exploring New Business Models with a Narrative Perspective. In 18th International Product Development Management Conference (Vol. 18).

26. Cheah, S. and Ho, Y.P., 2019. Coworking and sustainable business model innovation in young firms. Sustainability, 11(10), p.2959.

27. Laasch, O., 2018. Beyond the purely commercial business model: Organizational value logics and the heterogeneity of sustainability business models. Long Range Planning, 51(1), pp.158183.

28. Yunus, M., Moingeon, B., \& Lehmann-Ortega, L. 2010. Building Social Business Models: Lessons from the Grameen Experience. Long Range Planning, 43(2-3): 308-325.

29. Martin, C.J., Upham, P. and Budd, L., 2015. Commercial orientation in grassroots social innovation: Insights from the sharing economy. Ecological Economics, 118, pp.240-251.

30. Boons, F. and Lüdeke-Freund, F., 2013. Business models for sustainable innovation: state-ofthe-art and steps towards a research agenda. Journal of Cleaner production, 45, pp.9-19.

31. Cohen, B. and Kietzmann, J., 2014. Ride on! Mobility business models for the sharing economy. Organization \& Environment, 27(3), pp.279-296.

32. Abhishek, V., Guajardo, J. and Zhang, Z., 2019. Business models in the sharing economy: Manufacturing durable goods in the presence of peer-to-peer rental markets. Available at SSRN 2891908 
33. Ritter, M. and Schanz, H., 2019. The sharing economy: A comprehensive business model framework. Journal of cleaner production, 213, pp.320-331.

34. Apte, U.M. and Davis, M.M., 2019. Sharing economy services: Business model generation. California Management Review, 61(2), pp.104-131.

35. Bashir, M. and Verma, R., 2016. Airbnb disruptive business model innovation: Assessing the impact on hotel industry. International Journal of Applied Business and Economic Research, 14(4), pp.2595-2604.

36. Vargas-Hernández, J.G., 2020. Uber's Strategy as a Competitive Business Model of Sharing Economy. In Sharing Economy and the Impact of Collaborative Consumption (pp. 97-115). IGI Global.

37. Richter, C., Kraus, S., Brem, A., Durst, S. and Giselbrecht, C., 2017. Digital entrepreneurship: Innovative business models for the sharing economy. Creativity and Innovation Management, 26(3), pp.300-310.

38. Barbu, C.M., Bratu, R.Ş. and Sîrbu, E.M., 2018. Business models of the sharing economy. Revista de Management Comparat International, 19(2), pp.154-166.

39. Botsman, R., Rogers, R., 2010. What's mine is yours - the rise of collaborative consumption. New York: HarperCollins.

40. Witt, A., Suzor, N. and Wikström, P., 2015. Regulating ride-sharing in the peer economy. Communication Research and Practice, 1(2), pp.174-190.a

41. Kenney, M. and Zysman, J., 2016. The rise of the platform economy. Issues in Science and Technology, 32(3), p.61.

42. Bardhi, F. and Eckhardt, G.M., 2012. Access-based consumption: The case of car sharing. Journal of consumer research, 39(4), pp.881-898.

43. Sundararajan, A., 2016. The sharing economy: The end of employment and the rise of crowdbased capitalism. MIT Press.

44. De Stefano, V., 2015. The rise of the just-in-time workforce: On-demand work, crowdwork, and labor protection in the gig-economy. Comp. Lab. L. \& Pol'y J., 37, p.471.

45. Hevner, A., vom Brocke, J. \& Maedche, A. Roles of Digital Innovation in Design Science Research. Bus Inf Syst Eng 61, 3-8 (2019). https://doi.org/10.1007/s12599-018-0571-z

46. Hjalmarsson, A. and Rudmark, D., 2012, May. Designing digital innovation contests. In International Conference on Design Science Research in Information Systems (pp. 9-27). Springer, Berlin, Heidelberg.

47. Schwarten, Geoff, Perini, Fernando, \& Comolli, Loic. (2011). The power of sharing: Exploring the digital sharing economy at the base of the pyramid. Ottawa: IDRC

48. Hevner, A.R., 2007. A three cycle view of design science research. Scandinavian journal of information systems, 19(2), p.4.

49. Linde, F.: Ökonomie der Information. Göttingen 2008 https://doi.org/10.17875/gup2008-212

50. Whitney, M. and Richter Lipford, H., 2011. Participatory sensing for community building. In CHI'11 Extended Abstracts on Human Factors in Computing Systems (pp. 1321-1326).

51. Gassmann, O., Frankenberger, K., and Csik, M. (2014). Revolutionizing the Business Model. In Management of the Fuzzy Front End of Innovation (pp. 89-97). Springer International Publishing.

52. Martin, C.J., 2016. The sharing economy: A pathway to sustainability or a nightmarish form of neoliberal capitalism?. Ecological economics, 121, pp.149-159. 
53. Geissinger, A., Laurell, C., Öberg, C. and Sandström, C., 2019. How sustainable is the sharing economy? On the sustainability connotations of sharing economy platforms. Journal of Cleaner Production, 206, pp.419-429.

54. Schor, J. 2014. "Debating the Sharing Economy," Great Transition Initiative (October 2014). http://www.greattransition.org/publication/debating-the-sharing-economy, last accessed 2020/04/25

55. Pouri, M.J. and Hilty, L.M., 2018. ICT-enabled sharing economy and environmental sustainability - a resource-oriented approach. In Advances and New Trends in Environmental Informatics (pp. 53-65). Springer, Cham.

56. Pouri, M.J. and Hilty, L.M., 2020. Digitally Enabled Sharing and the Circular Economy: Towards a Framework for Sustainability Assessment. In Advances and New Trends in Environmental Informatics (pp. 105-116). Springer, Cham.

57. Plewnia, F. and Guenther, E., 2018. Mapping the sharing economy for sustainability research. Management Decision.

58. Demailly, D.; Novel, A.S. The Sharing Economy: Make it Sustainable; IDDRI: Paris, France, 2014; Volume 3

59. Heinrichs, H. Sharing economy: A potential new pathway to sustainability. Gaia 2013, 22, 228-231.

60. Maedche, A., S. Gregor, S. Morana and J. Feine (2019). "Conceptualization of the Problem Space in Design Science Research". In: Extending the Boundaries of Design Science Theory and Practice. Ed. by B. Tulu, S. Djamasbi, G. Leroy. Cham: Springer International Publishing, pp. 18-31.

61. Iivari, J., 2015. Distinguishing and contrasting two strategies for design science research. European Journal of Information Systems, 24(1), pp.107-115.

62. Matzler, K., Veider, V. and Kathan, W., 2015. Adapting to the sharing economy. MIT Sloan Management Review, 56(2), p.71.

63. Yaraghi, N. and Ravi, S., 2017. The current and future state of the sharing economy. Available at SSRN 3041207.

64. Piscicelli, L., Cooper, T. and Fisher, T., 2015. The role of values in collaborative consumption: insights from a product-service system for lending and borrowing in the UK. Journal of Cleaner Production, 97, pp.21-29.

65. Gansky, L., 2010. The mesh: Why the future of business is sharing. Penguin.

66. Puschmann, T. and Alt, R., 2016. Sharing economy. Business \& Information Systems Engineering, 58(1), pp.93-99.

67. Belk, R. (2014) You are what you can access: Sharing and collaborative consumption online. Journal of Business Research, Volume 67, No. 8, pp.1595-1600.

68. Belk, R., (2014). Sharing versus pseudo-sharing in Web 2.0. The Anthropologist, 18(1), pp.723.

69. Alt, R. and Zimmermann, HD. 2001. "Introduction to Special Section - Business Models," Electronic Markets (11:1), pp. 3-9.

70. Lambert, S., 2006. A business model research schema. BLED 2006 Proceedings, p.43.

71. Bailey, K. D. (1994). Typologies and Taxonomies: An Introduction to Classification Techniques. Los Angeles, Sage Publications Inc.

72. Lan, J., Ma, Y., Zhu, D., Mangalagiu, D. and Thornton, T.F., 2017. Enabling value co-creation in the sharing economy: The case of mobike. Sustainability, 9(9), p.1504. 
73. Hamari, J., Hanner, N. and Koivisto, J., 2020. " Why pay premium in freemium services?" A study on perceived value, continued use and purchase intentions in free-to-play games. International Journal of Information Management, 51, p.102040.

74. Newlands, G., Lutz, C. and Fieseler, C., 2018. Navigating peer-to-peer pricing in the sharing economy. Available at SSRN 3116954.

75. Zhang, T.C., Gu, H. and Jahromi, M.F., 2019. What makes the sharing economy successful? An empirical examination of competitive customer value propositions. Computers in Human Behavior, 95, pp.275-283.

76. Zhang, T.C., Jahromi, M.F. and Kizildag, M., 2018. Value co-creation in a sharing economy: the end of price wars?. International Journal of Hospitality Management, 71, pp.51-58.

77. Hamari, J., Sjöklint, M. and Ukkonen, A., 2016. The sharing economy: Why people participate in collaborative consumption. Journal of the association for information science and technology, 67(9), pp.2047-2059.

78. Pouri M.J. and Hilty, L.M. 2020. The Relevance of Digital Sharing Business Models for Sustainability. In Proceedings of the 7th International Conference on ICT for Sustainability (ICT4S 2020). ACM, New York, NY, USA, 11 pages. https://doi.org/10.1145/3401335.3401344.

79. Hilty, L.M. and Aebischer, B., 2015. ICT for sustainability: An emerging research field. In ICT innovations for Sustainability (pp. 3-36). Springer, Cham.

80. Hilty, L. M.; Wäger, P.; Lehmann, M.; Hischier, R.; Ruddy, T.; Binswanger, M. 2004. The future impact of ICT on environmental sustainability. Fourth Interim Report - Refinement and quantification. Institute for Prospective Technological Studies (IPTS), Sevilla.

81. Kim, K., Baek, C. and Lee, J.D., 2018. Creative destruction of the sharing economy in action: The case of Uber. Transportation Research Part A: Policy and Practice, 110, pp.118-127.

Appendix 1: A sample of digital sharing platforms and their business model codes based on the proposed typology of digital sharing platforms. Platforms may offer several types of service. In these cases, the table refers to the most resonating service type of the platform.

\begin{tabular}{llll}
\hline Platform & URL & Area of service & $\begin{array}{l}\text { Business } \\
\text { Model Code }\end{array}$ \\
\hline Airbnb & https://www.airbnb.com & Lodging, hospitality & (F1, T1, W1, H4) \\
CouchSurfing & https://www.couchsurfing.com & Lodging, homestay & (F1, T1, W1, H2) \\
Fon & https://fon.com & Wi-Fi network & (F1, T1, W1, H3) \\
$\begin{array}{l}\text { Too Good To } \\
\text { Go }\end{array}$ & https://toogoodtogo.org & Avoiding food waste & (F2, T1, W2, H4) \\
TaskRabbit & https://www.taskrabbit.com & Personal service & (F1, T1, W3, H4) \\
hOurworld & https://hourworld.org & Time bank & (F1, T1, W3, H3) \\
Cohealo & https://cohealo.com & Healthcare & (F4, T4, W1, H4) \\
Zipcar & https://www.zipcar.com & Mobility- car sharing & (F2, T1, W1, H4) \\
\hline
\end{tabular}

